\title{
On Using Functional Genetics to Understand Breast Cancer Biology
}

\author{
Kornelia Polyak \\ Department of Medical Oncology, Dana-Farber Cancer Institute, Harvard Medical School, Boston, \\ Massachusetts 02215 \\ Correspondence: kornelia_polyak@dfci.harvard.edu
}

$T^{\mathrm{h}}$ he completion of the human genome project has greatly accelerated discovery of novel genes and their structural abnormalities implicated in various human diseases, including cancer, but it has not revealed much information about their functions. Even if we just consider coding genes, which constitute only a small part of the genome, our understanding of their physiologic roles is limited to a fraction of them. Functional genomics studies, aimed at the identification and characterization of all genes in the genome based on their function, until recently could only be conducted in lower organisms, as large-scale screens were not feasible in mammalian cells. This all changed about a decade ago with the discovery of RNA interference (RNAi). Since then this technology has been one of the most useful and fruitful tools in cancer research.

Ashworth and Bernards (2011) provide an excellent overview of recent functional genomics studies of breast cancer and other human cancers that aimed to identify novel tumor suppressors and oncogenes and to dissect the molecular basis of therapeutic resistance and tumor progression. Initially such screens involved small sets of genes based on their known biochemical functions (e.g., deubiquintylating enzymes) or relatively easy "druggability" (e.g., kinases and G-protein-coupled receptors [GPCRs]), but more recently genome-wide screens have been feasible even in human cells. However, with the everincreasing number of noncoding RNAs uncovered and numerous alternative transcripts for each gene, the definition of "genome-wide" is becoming more and more difficult, as is confirmation that specific targeting has been achieved (especially challenging for certain groups of noncoding RNAs and alternative transcripts).

Ashworth and Bernards discuss several examples of loss-of-function and gain-of-function screens and provide a detailed description of the technical aspects of these studies. The discussion of potential technical problems is especially useful, because these technologies promise to provide solid preclinical data for future clinical studies. However, translating the results is still limited by the availability of suitable drugs, although the potential therapeutic use of short hairpin RNA (shRNA) and RNAi is also being explored.

One of the most exciting applications of RNAi screens is to identify synthetic lethal interactions in cancer cells as this approach would ensure tumor specificity and minimize side effects. Among all synthetic lethal interactions identified thus far in tumors (although this was not discovered in a functional genomics screen), the discovery that inhibition of poly(ADP-ribose) polymerase (PARP) selectively kills BRCA1- or BRCA2-deficient cancer cells (Farmer et al.

Editors: Mina J. Bissell, Kornelia Polyak, and Jeffrey M. Rosen

Additional Perspectives on The Mammary Gland as an Experimental Model available at www.cshperspectives.org

Copyright (C) 2012 Cold Spring Harbor Laboratory Press; all rights reserved; doi: 10.1101/cshperspect.a013516

Cite this article as Cold Spring Harb Perspect Biol 2012;4:a013516 
K. Polyak

2005) has had the most clinical impact. Based on promising preclinical studies, several clinical trials are under way using various PARP inhibitors in breast cancer (BRCA) patients and there are promising preliminary results. The use of PARP inhibitors in BRCA patients also represents one of the fastest translations of a basic science finding into clinical practice, providing a proof of principle for rational personalized medicine. The rapid advances in screen design and complementary technologies (e.g., singlemolecule sequencing) provide hope that many more success stories like this will follow in the near future.

\section{REFERENCES}

${ }^{*}$ Reference is also in this collection.

* Ashworth A, Bernards R. 2011. Using functional genetics to understand breast cancer biology. Cold Spring Harb Perspect Biol doi: 10.1101/cshperspect.a003327.

Farmer H, McCabe N, Lord CJ, Tutt AN, Johnson DA, Richardson TB, Santarosa M, Dillon KJ, Hickson I, Knights C, et al. 2005. Targeting the DNA repair defect in BRCA mutant cells as a therapeutic strategy. Nature 434: 917-921. 


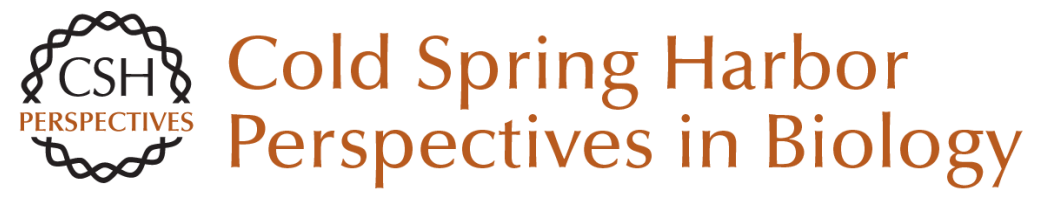

\section{On Using Functional Genetics to Understand Breast Cancer Biology}

Kornelia Polyak

Cold Spring Harb Perspect Biol 2012; doi: 10.1101/cshperspect.a013516

Subject Collection The Mammary Gland as an Experimental Model

On the Role of the Microenvironment in Mammary Gland Development and Cancer Derek Radisky

On Using Functional Genetics to Understand Breast Cancer Biology Kornelia Polyak

On Oncogenes and Tumor Suppressor Genes in the Mammary Gland Rushika M. Perera and Nabeel Bardeesy

On Leukocytes in Mammary Development and Cancer Cyrus M. Ghajar

On Chromatin Remodeling in Mammary Gland Differentiation and Breast Tumorigenesis Kornelia Polyak

On Hormone Action in the Mammary Gland J.M. Rosen

TGF- $\beta$ Biology in Mammary Development and Breast Cancer

Harold Moses and Mary Helen Barcellos-Hoff

A Compendium of the Mouse Mammary Tumor Biologist: From the Initial Observations in the House Mouse to the Development of Genetically Engineered Mice

Robert D. Cardiff and Nicholas Kenney
On How Mammary Gland Reprogramming

Metalloproteinases Couple Form with Function Bonnie F. Sloane

On Molecular Mechanisms Guiding Embryonic Mammary Gland Development Gertraud W. Robinson

On Stem Cells in the Human Breast Mark A. LaBarge

On Murine Mammary Epithelial Stem Cells:

Discovery, Function, and Current Status Jeffrey M. Rosen

On In Vivo Imaging in Cancer David Piwnica-Worms

Choosing a Mouse Model: Experimental Biology in Context--The Utility and Limitations of Mouse Models of Breast Cancer Alexander D. Borowsky

Mammary Gland ECM Remodeling, Stiffness, and Mechanosignaling in Normal Development and Tumor Progression Pepper Schedin and Patricia J. Keely

Molecular Mechanisms Guiding Embryonic

Mammary Gland Development Pamela Cowin and John Wysolmerski

For additional articles in this collection, see http://cshperspectives.cshlp.org/cgi/collection/

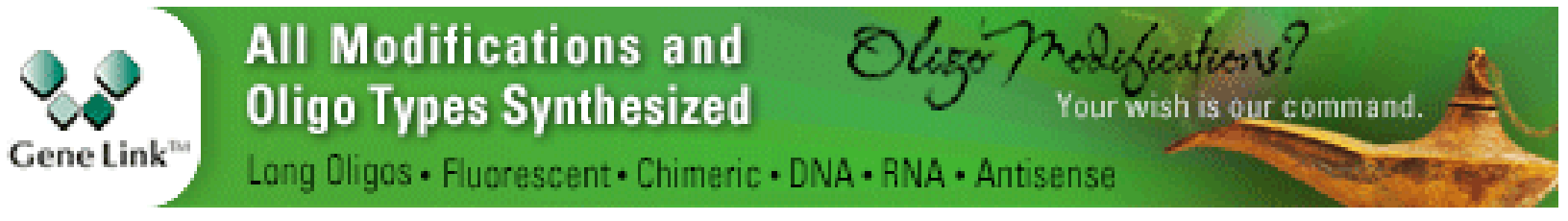


For additional articles in this collection, see http://cshperspectives.cshlp.org/cgi/collection/

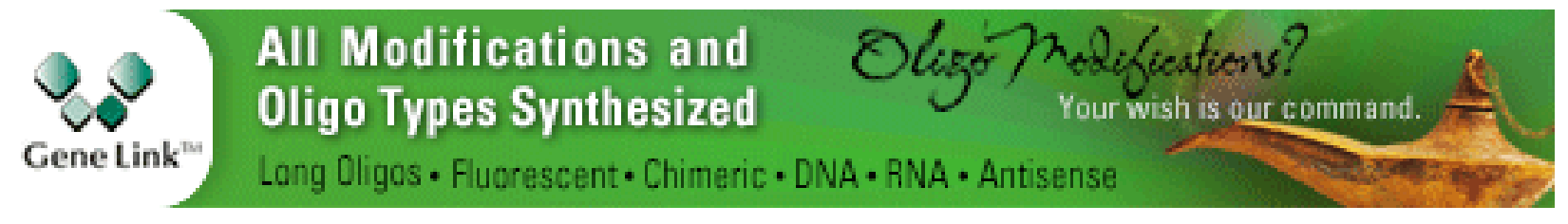

Copyright @ 2012 Cold Spring Harbor Laboratory Press; all rights reserved 